\title{
'But is it good?' Why Aesthetic Values Matter in Sociological Accounts of Tastes
}

\author{
Laurie Hanquinet ${ }^{1 *}$
}

\section{University of York, UNITED KINGDOM}

*Corresponding Author: laurie.hanquinet@york.ac.uk

Citation: Hanquinet, L. (2018). 'But is it good?' Why Aesthetic Values Matter in Sociological Accounts of Tastes, Journal of Cultural Analysis and Social Change, 3(2), 09. https://doi.org/10.20897/jcasc/3990

Published: December 22, 2018

\begin{abstract}
If the relation between social position, cultural capital and tastes is well known in the literature, many accounts of tastes do not bother to examine the aesthetic dimension of the cultural capital. Yet, people are immersed during their lives within a multiplicity of aesthetic values that are processed into aesthetic dispositions that orient their cultural choices. This article develops a theoretical model for taste-making that helps us examine the implications of why aesthetic values should be taken seriously. First these values are historically situated and hence are bound to change over time. This means that the definitions of our conceptual tools, such cultural capital and highbrow culture, need to be monitored and updated when necessary. Although they are rooted in social transformations, these values acquire a force of their own and motivate people's cultural preferences. This matters since these values also participate in the delimitation of what is perceived as good, bad, right and wrong in society. In short, I argue that tastes are influenced by people's social position but in a much more indirect way than has often been assumed.
\end{abstract}

Keywords: cultural capital, taste, morality, aesthetics, habitus

\section{INTRODUCTION}

When we encounter a painting, or listen to a song, we try and decode it, attach a value to it, and assess it. Is it beautiful? Ugly? This is the kind of evaluation we do every day - consciously or not - in order to make sense of our cultural landscape. Sociologists have taken an interest in this process and have been keen over the years to demonstrate that it is as much a social as it is an aesthetic one (if not more). Key figure among them, Bourdieu sought to challenge the idea inspired by a Kantian aesthetic that 'pure' taste, as the ability to judge the beautiful and what is aesthetically 'good', was disinterested and was claiming to universality. Instead, showing how tastes were socially determined, he argued that 'Kant [has an] inclination to identify the universal with the universe of cultivated people' (1984, p. 599).

Since Bourdieu's demonstration, many sociological accounts have privileged what Woodward and Emmison call 'studies of objectified tastes' (2001) that relate people's cultural preferences to their socio-economic characteristics in a quite systematic way. These approaches have been essential in helping people grasp the importance of these cultural preferences in understanding social inequalities and the way these preferences act as markers of social position. However, they have relied on a reductive vision of aesthetic principles in which 'high' and 'low' cultures have become robbed of all intrinsic value and simply defined by the symbolic value given to people who like them. Taking the example of art, Ted Cohen showed very well the problem of such an approach. 
What makes the high art high? Is it that its appeal is mostly to high audiences? Then what makes the audience high? 'That its taste is for high art? Well, of course, that makes a circle.' (Cohen, 1999, p. 142)

Cohen suggests that this circular reasoning leaves many questions about the meaning of cultural tastes unanswered. This paper represents an attempt to better understand how tastes for cultural and artistic objects or activities $^{\mathrm{i}}$ get formed. Cultural tastes are considered here as observable practices which constitute a key part of people's lifestyleii (i.e. what people like in music, art, etc. and what to appreciate to do as cultural activities).

Most sociological research on cultural preferences has avoided examining the aesthetic structures and criteria underlying them, leaving these to art philosophers and historians. Even some of the most iconic works in the sociology of art have adopted a value-free sociology, Becker's 'art worlds' (1988) being a perfect example. The article aims to outline the main reasons why aesthetic values should be taken seriously by researchers seeking to understand the formations of tastes. They should be seen as linked to questions of social power (and hence not universal) but not reducible to them (Harrington, 2004, p. 53). They refer here to values that define the boundaries between art and non-art and between good and bad art (e.g. beauty, skills, originality, reflexive power, etc.) and should be distinguished from aesthetic experiences, as explained in the first section of the article. The article presents a theoretical model to account for the making of tastes. Its starting point, which, in my view, still deserves to be thoroughly emphasised, is that, following Bourdieu's theory of cultural capital (1979a), aesthetic values are internalized into schemes of dispositions that guide people in the formation of their tastes and influence how people classify what is art, what is worthy of interest, what is sophisticated and refined and what is not (i.e. people's internal aesthetic classifications). If aesthetic values are examined seriously, it will become clear that these values are historically situated and hence are bound to change over time. This implies that the definitions of our conceptual tools, such cultural capital and highbrow culture, need to be monitored and updated when necessary. This matters even more once we understand that these values also participate in the delimitation of what is perceived as morally good, bad, right and wrong in society.

\section{FIRST A NOTE ON THE DIFFERENCE BETWEEN AESTHETIC EXPERIENCES AND AESTHETIC CLASSIFICATIONS}

Before any discussion on the role of aesthetics in shaping cultural tastes, there is a need to distinguish between what could be called 'aesthetic classifications' and 'aesthetic experiences' as they refer to different objects of study. Aesthetic classifications can be associated with Bourdieu's work on 'Distinction' (Bourdieu, 1979a). He shows how tastes cannot only reflect people's natural inclinations but also act as social markers since they reflect aesthetic principles that are socially valued or not. Bourdieu's theory gives a complex picture of the - French - class society in the 1970s showing how social position is built upon different forms of resources, economic, cultural, social, and, eventually, symbolic (i.e. social prestige). He particularly underlines the importance of cultural capital and its different forms - institutionalized through degrees and diplomas, objectified in cultural objects and goods (e.g. paintings), and embodied in social dispositions, knowledge, skills (e.g. 'appearing to be cultured') - in the production and maintenance of social stratification and inequalities (Bourdieu, 1979b). Indeed those brought up in a culturally rich milieu are more likely to develop an 'aesthetic disposition', i.e. an ability 'to "decode" the formal [aesthetic] structure of the cultural work' (Lizardo, 2008, p. 2), and to acquire cultural skills through the 'habitus' that enable them to secure more easily potentially advantageous degrees. Habitus converts people's social origin and position into a set of socially learnt dispositions, skills and ways of acting. It makes the link between the social space and the lifestyle space in Bourdieu's theory.

In comparison, Hennion and DeNora's work is distinctive in the study of aesthetic experiences, which, for some, are more telling than simply examining 'patterns of cultural transmission' supposedly à la Bourdieu (Kaszynska, 2014). Their research focuses on the interactions between the object and the subject and how both are produced and transformed by these interactions. If we take the example of music, it is shaped through the meanings listeners 'attach' to it when they experience it at given moments (Hennion, 2007). The distinction between music listener and creator as well as that between the object and the subject become blurred: first, the meaning attached to music is not a given but results from a mutually constitutive relationship (or 'reflexive activity' Hennion would say) that attaches together an individual keen to experience and an object ready to surprise; second, music contributes to the development of the self (DeNora, 1999).

These approaches of aesthetic experiences are most certainly valuable because they take the artwork seriously. DeNora's perspective reveals how music has aesthetic properties that act in people's everyday life. For instance, some music pieces are capable of generating specific emotions (2000). Arguably in line with Dewey's conception of aesthetic experience (Strandvad, 2012), Hennion's theory of attachment (Hennion, 2001) tells us in comparison less about how and why specific aesthetic properties and structures of artworks become activated in the transformative encounter between the subject and the object. To put it bluntly, focusing on the experience, we 
know what music does to us (and what we do to music) but not much how. I agree with Born's critique of these interactionist approaches and that 'the microsocial has to be re-connected with the macro-social, and with historical analysis' (2005, p. 22). Therefore, it does not suffice to explore tastes as an individual aesthetic experience which would be first and foremost subjective; there is also a need to recognize that people's tastes are inscribed within aesthetic boundaries that are socially and historically situated.

\section{FOUR PROPOSITIONS FOR A THEORETICAL MODEL OF TASTE-MAKING}

This article identifies key propositions about the individual process of taste-making made in the literature and brings them together in a comprehensive model. The model developed here links social origin (i.e. how people have been brought up) and position (i.e. current position in the social hierarchy) to tastes as practices but in a more complex way than many current approaches assume. It outlines the importance of aesthetic values - embedding moral conceptions - in the formation of people's cultural capital and tastes and recognizes the historical determinations of aesthetic judgements. It is summarized in Figure 1 but this figure should only be conceived as a communication tool whose function is to help the readers follow my reasoning. The mechanisms I am seeking to unravel are more complex than in this representation but, once this is established, the graphical representation of my arguments (not of the 'reality') can be used for the sake of clarity.

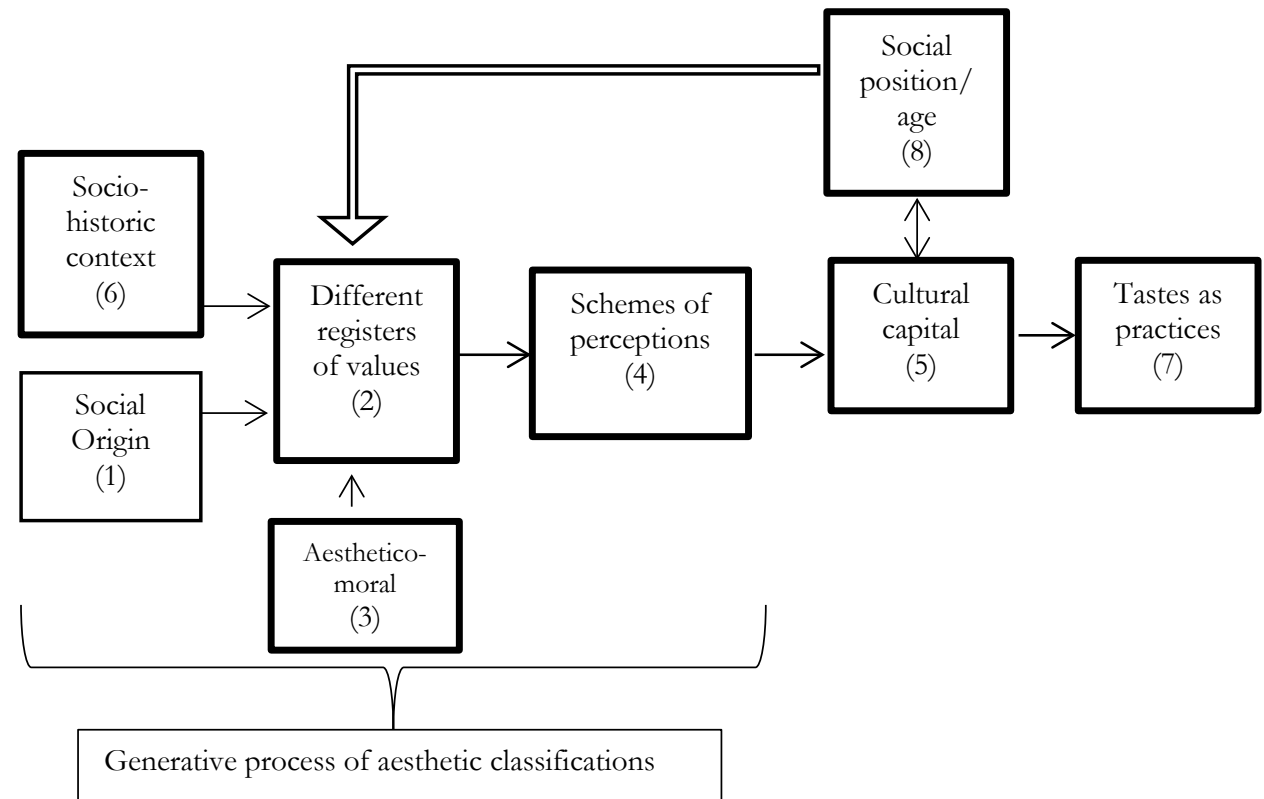

Figure 1. Model to account for tastes: graphical representation

My starting point is that those like me who believe that people's differences in tastes and lifestyles are related to differences in cultural capital or resources often overlook the fact that these resources include specific aesthetic values and a disposition to rely on them. Once one accepts the premise that cultural capital has an important aesthetic dimension, there is a need to understand the process through which some values become important in people's aesthetic classifications at some moments in time and why certain groups adhere to them and others not. How do these values reconfigure cultural capital and hence tastes hierarchies? We know what is happening but it is less clear how. In a way, all the pieces of the puzzle discussed below will be known to cultural sociologists - and I do not claim originality here - but there is still an urgent need to think about how to articulate them with each other.

\section{Proposition 1: Aesthetic Values are Historically Situated}

Figure 1 tells us that different registers of values (2), including important aesthetico-moral ones (3), are available in society for individuals to build their own judgments on cultural forms (or their schemes of perceptions or dispositions - 4) and hence their tastes (7). An example of these would be that art should be attached to a serious and disinterested pleasure. Whether or not this value is being embodied in people's cultural capital (5) through a disposition to appreciate serious art depends on their social origin (1) and position (8). Friedman (2011) showed how this disposition is sought after in specific comedy shows by those in privileged positions. Yet, my point here is that these values are not only socially but also historically situated (6). The idea of art as a serious and disinterested pleasure emerges at a certain point in time, with the rise of modernism in the $19^{\text {th }}$ century (Esquivel, 2008). What makes high art high can then in part be unravelled by a look at history. 


\section{Proposition 2: Aesthetic Values Acquire a Semi-autonomous Force}

I will also argue that, although aesthetic values are shaped in a specific social and historical context (hence through social forces), they develop a force of action of their own, which has often been ignored in cultural sociology. They become principles of action that help unconsciously shape people's tastes and guide their reactions to an encounter with a cultural good in specific contexts and interactions. For instance, people appreciate van Gogh's work because they appreciate the aesthetic values that it embodies (e.g. technical virtuosity or expressivity) not just because it is socially considered as high art. These aesthetic values become important in themselves and sociology needs to take stock of them.

\section{Proposition 3: The Concept of Cultural Capital, Given its Important Aesthetic Dimension, is in Constant Need of an Update}

The register of aesthetic values on which people draw for their judgments of taste is then bound to change over time. New aesthetic paradigms emerge all the times and keep changing the society's aesthetic and cultural classifications (the latter being the social ranking of cultural genres). This will inevitably alter the meanings associated to cultural capital (especially under its embodied form) and to highbrow culture.

\section{Proposition 4: Aesthetic Values are Intrinsically Bound up with Moral Values}

If aesthetic values cannot be perceived as universal anymore, they nevertheless play their own and substantial role in cultural production and reception. Such role becomes even more visible when one considers that aesthetic values are intrinsically bound up with moral values, as I will argue later in this article. In defining 'the good taste' and 'the bad taste', they also draw lines between 'the [morally] good' and 'the [morally] bad' more generally. Aesthetic values are essential in shaping possible forms of togetherness and are not perceived here as detached from the moral sphere. Following Vaisey's 'dual-process model of culture in action' (2009), I will show that such links between the aesthetic and the ethical are visible at different levels of consciousness. If they are visible in people's explicit accounts of their tastes, they are even more important in constituting a practical consciousness that guides people's action. Taking van Gogh's example again, his aesthetic excellence comes in part from the 'sacrifice' he made through his life and work in oder to reveal to us the madness of our society (Heinich, 1991).

\section{STARTING POINT: TAKING SERIOUSLY THE AESTHETIC VALUES IN CULTURAL CAPITAL}

In order to understand the role of cultural capital in taste-making, I need to briefly first discuss the notion of habitus. Bourdieu's habitus (1979a) is the mechanism through which external environments are processed at the individual level into specific perceptions, appreciations, and actions (Lizardo, 2004). Cognitive sociology tells us that part of the role of the habitus is to perceive and collect raw information from the environment and to transform it into schemata, which are representations of the world people live in at a certain moment in time and can influence people's action (Lizardo, 2004). This constitutes some sort of tacit cultural knowledge that influences the type of resources (or capital) they gain access to or develop (especially in terms of embodied cultural capital, Bourdieu, 1979b). As DiMaggio (1997, p. 267) put it, this knowledge or 'representations of culture' form a "toolkit" (Swidler, 1986) or "repertoire" (Tilly, 1992): a collection of stuff that is heterogeneous in content and function'. In line with this view, I consider here that this repertoire includes aesthetic values and classificatory principles that guide people's perceptions and judgements of cultural products and, importantly, is shaped to some extent by the social trajectories of people within the social field. Hence, people's dispositions to appreciate cultural forms (or schemes of perception), which eventually shape our cultural preferences and form part of our embodied cultural capital, are engrained in different registers of aesthetic values (see Figure 1).

As discussed in previous work (Hanquinet et al., 2014), Bourdieu's theory refers to two main aesthetic registers, the highbrow and the popular aesthetics. They are endorsed by different class fractions defined by specific configurations of cultural, economic and social capital. The highbrow aesthetic echoes the Kantian principle of disinterestedness and pays more attention to the form than to the content of art. It emphasizes the autonomy of art as it should appear detached from everyday life. In line with the idea of 'art for art's sake', distance, detachment and affective neutralization are core conditions to enjoy art. At the opposite, the popular aesthetic draws on the idea that art should evoke or represent something tangible. Popular art is immediate, concrete and emotionally tainted (and not in a disinterested way). While some see this vision of popular culture as an 'anti-aesthetic' (Bennett et al., 2009; Shusterman, 1991) ${ }^{\mathrm{iii}}$, Bourdieu's aesthetic classification nevertheless contains some substance in the sense that it avoids a circular reasoning that defines the value of tastes only by the characteristics of those who consume them. His emphasis on the role of autonomy in the cultural field reveals his ambiguous position towards highbrow aesthetics (Ahearne, 2004, p. 71): he helped de-mystify its supposedly sacred nature and showed its links 
with the field of power but still perceived it as a tool for emancipation and enlightenment (Chaumier, 2010) that should be valued (Stewart, 2012)

Importantly, Bourdieu's own definition of cultural capital relies on an implicitly historicized vision of aesthetic values, reflecting the ways he interpreted the state of the cultural field at a specific moment in time. Unfortunately, the relational vision of the aesthetic underlying his concept of cultural capital has been progressively obscured by the repetitive use of fixed definitions of popular and highbrow culture. The latter is still being frequently defined as art museum visiting, taste for classical music, opera and art book reading, as if, in almost 40 years (since Distinction), highbrow culture could not change. Yet, for Bourdieu, these aesthetic principles related to the development of the field of cultural production. This field is in constant flux and new aesthetic paradigms have appeared. In addition, the rise of the consumer and digital society has radically transformed the breadth and composition of the range of cultural goods one can have access to. These developments can modify the ways we perceive and classify cultural products and ultimately what constitutes our cultural capital. Let us now take a closer look at the historical process through which certain values over others become praised as a sign of quality of art at a certain moment in time and the ways in which these aesthetic classifications participate in the formation of individual preferences.

\section{Proposition 1: The Socio-historical Genesis of Individual Aesthetic Preferences}

As Wacquant (1996, p. XVI) suggested, history is embodied in the habitus. Hence, aesthetic values are more than the reflections of people's status and the aesthetic schemata or dispositions that orient people's tastes mirror the socio-historical context of cultural production and can also help change it if one also sees the habitus as 'actiongenerative' like Lizardo does (2004).

Different authors have demonstrated how the aesthetic criteria we rely on are the product of a historical moment. DiMaggio (1982), for instance, shows the role of new urban elites in the institutionalization of highbrow culture in Boston at that time. Levine (1990) explains further how the very notion of 'highbrow culture' emerged at the end of the $19^{\text {th }}$ century in the United States as the result of different transformations in the sphere of cultural production that echoed in the sphere of cultural consumption (autonomization and sacralization of culture, opposition to any mixing of genres, depreciation of popular forms of culture, distanciation from an unknowledgeable audience, etc.). These processes were also linked to the emergence of new fractions of class who used their cultural capital to affirm their social position. An important point though is that Levine has never denied the role of aesthetics in these changes but contends that aesthetics cannot explain alone changes in behaviours and attitudes and in the institutional settings that went along with the establishment of high culture (p. 228).

This illustrates the fragile and dynamic nature of the aesthetic and cultural classifications we use, even when they have been supported by longstanding institutions. An example of this is the 2018 Pulitzer prize for music that was not awarded to a classical or jazz musician but to a rapper for the first time, Kendrick Lamar. Lamar is presented as a sophisticated and genuine composeriv and his work as aesthetically refined as legitimate classical music can be; yet, this critical success also means the introduction of new aesthetic values, his music being praised for its 'vernacular authenticity'v or its explicit social relevance with its storytelling force vi. It also shows how the field of cultural consumption - where tastes are expressed - is intrinsically related to the field of cultural production from where new principles of perception and appreciation can be validated (Lizardo, 2008). While rap and hip hop have for long been considered as a lowbrow or popular genre with little aesthetic value (Bryson, 1996), its appreciation has increased over time (Lizardo and Skiles, 2015) and some sort of connoisseurship of the genre may shortly become a distinctive resource.

\section{Proposition 2: Aesthetic Values: A Force of their Own}

From above, it is clear that new aesthetic values are rooted in social transformations and hence have a social dimension. Yet, once formed, aesthetic values have a force of their own, as they are in various ways integrated in people's practical consciousness and this guides them in their everyday encounters with cultural goods. They form 'moralcultural scripts' that shape 'one's "gut" responses to the possibilities raised in particular interactions' (Vaisey, 2008, p. 1705). In the same way Vaisey showed how moral values (or schemas) influence teenagers' behaviours, I argue here that aesthetic values are 'cultural forces in ways that [people] are largely unaware of and [often] unable to articulate but that nevertheless shape their [...] judgments' (idem, p. 1704) (forming this practical consciousness). I will come back to Vaisey's theory in the section on morality.

Hence, aesthetic values could not simply be reduced to the socio-historical conditions from which they emerge (Harrington, 2004). Disputing the idea of aesthetic universalism, Stewart (2012) recognizes the context within which aesthetic values are embedded in but also seeks to outline that sociologists should still account for aesthetic values. Otherwise, the cultural object runs to risk to 'disappear' under the threat of cultural relativism. To put it simply, high art is high not just because its audience is high (-status). Similarly, Wolff (2008) aims to develop an aesthetic theory that would recognize the socially situated character of aesthetic values -as unravelled by critical 
theory (race, gender and postcolonialism). Her 'aesthetic of uncertainty' avoids the temptation of 'falling back on discredited notions of timeless beauty and universal values' (p. 18) but would still offer tools to understand the role of aesthetic values (composition, form, originality) in the production and reception of art: 'Curators, museum directors, publishers [...], confronted by the new postmodern relativist aesthetic, still have to continue their work as cultural mediators [...]. [...] [T] hey surely need to be able to defend their choice in aesthetic [...] terms' (p. 21).

While many may find it difficult to discursively describe/ justify their gut reactions to a cultural object, experts may more easily account for what motivates their instinctive responses to a cultural object. If their work reveals how values can help justify tastes (so after the fact), they may also hint, I would contend, at how they can be part of a practical consciousness guiding our preferences. In his Guardian article 'Sorry MoMA, video games are not art' $(30 / 11 / 12)^{\text {vii }}$, the British art critic, Jonathan Jones, reacts very negatively ('gut feelings') to the decision of the Museum of Modern Art in New York to collect and exhibit games. The quote below reflects how very specific aesthetic criteria have informed his judgment of taste. Video games cannot be art because they do not translate personal authorship and imagination. According to him, games have been considered as art by some art theorists who have emphasized 'their interactive dimension and liberation of shared authorship' (Jones, 2012), which he disagrees strongly with. While a game's purpose can be found in its interactivity with an audience, an artwork, suggests Jones, can exist on its own, as a reflection of an artist's creative power.

Walk around the Museum of Modern Art, look at those masterpieces it holds by Picasso and Jackson Pollock, and what you are seeing is a series of personal visions. A work of art is one person's reaction to life. Any definition of art that robs it of this inner response by a human creator is a worthless definition. Art may be made with a paintbrush or selected as a ready-made, but it has to be an act of personal imagination.' (Jones, 2012)

The aesthetic rhetoric used here echoes some values inscribed in the modernist principle of art of art's sake, where the artist frees her- or himself in a pure act of self-expression. In a counter-piece, Keith Stuart (06/12/12) viii, the Guardian's games editor and now renowned novel author, accuses the art critic of being 100 years behind (I am paraphrasing here) and, while he asks whether the question of game as art matters in fine, he presents compelling counter-arguments, including the idea that all art is collective (interestingly resonating with Becker's analysis of the art worlds), and outlines the increasingly emphasized participative, interactive, experiential and communicative dimensions of art (see for instance Bourriaud 2003) that would give video games legitimacy as art. Interestingly as well, Stuart somewhat regrets the predominant focus in visual design taken by the MOMA in its initial selection of games, rather than also considering the meaning of games. Concepts seem to matter for game experts as much as design; this is arguably in line with the development of conceptual art since the last century.

What we see in this example is a conflict between aesthetic values or, even, aesthetic paradigms. My point here is that these values shape these experts' tastes in a way that cannot simply be explained by their social position (they are both cultural experts), by the educational background (they are both highly educated) or, even, by their age (at first sight, there does not seem a huge generational gap either). Both sets of values have emerged at different times in history but have also co-existed and gained validity in the art field for a while now. They can nowadays both compete in the artistic evaluation of the same objects. As Daenekindt (2017) suggests, the way people internalise publicly available aesthetic values may not be related to traditional social divisions, at least not directly. These divisions may, I argue, have instead a role in delimiting the possible repertoire of values from which different social groups draw. Moreover, these critics, who are the most typical 'cultural intermediaries' according to Bourdieu (1979a, p. 359), represent the bridge through which these aesthetic values can be distilled more subtly into a wider population. As we know, cultural intermediaries can, through their expertise, frame what is worthy of interest and impact on cultural hierarchies (Maguire and Matthews, 2012, p. 559). They diffuse aesthetic criteria in the public sphere that can be progressively incorporated in other people's everyday dispositions towards art.

This example illustrates how aesthetic values are involved in shaping people's tastes. While their understanding requires us to contextualize them, these values have achieved a semi-autonomous ${ }^{\text {ix }}$ force on tastes that cannot be reduced to the social position or origin of those who have incorporated them. This is only in recognizing their specific role that we can approach tastes as the ever-changing battleground of competing aesthetic paradigms and that we can envisage the possible coexistence of different forms of highbrow aesthetics (Hanquinet, 2017).

\section{Proposition 3: Bringing Aesthetic Values Up-to-date}

We have seen so far that the repertoire of aesthetic values changes overtime due to social innovations and transformations, while acquiring a force of their own. This has implications with regard to the substantive meaning that is given to Bourdieu's conceptual tools, especially cultural capital and highbrow culture. Although Bourdieu's concepts are still essential for their capacities to unravel hidden mechanisms, Prior rightly contends that 'we need to find satisfactory ways of updating and warping [Bourdieu's] ideas to account for inflections in the cultural landscape' (2005, p. 125). 
Bourdieu's definition of highbrow culture draws on an implicitly modernist aesthetic and, as Prior argued (2005), his account of art perception should be updated to account for the rise of postmodern cultural values (e.g. entertainment or distraction). Modernism has challenged the traditional characteristics of works of art, such as representation, harmony and beauty, and artistic skills, endorsed the 'Art-for-the-art's sake' principle valuing detachment in arts consumption and stressed the autonomy of works of art. Although this paradigm is still influential, new ones have emerged. In particular (but among others) postmodernism questions the gap between the commercial and popular on the one hand and the highbrow on the other and promotes a 'playful' aesthetic based on transgression and experimentation (Esquivel, 2008; Featherstone, 1991). It also seeks to reduce the boundaries between life and art, enabling more participative, inclusive and immediate forms of art and culture. As argued elsewhere (Hanquinet et al., 2014), this has transfigured the content one should give to highbrow culture as it can include both classical and 'emerging' cultural referents. We have, for instance, shown that new dimensions can be crucial in the development of distinctive aesthetic preferences, such as one that privileges a socially explicit reflexive art compared to art detached from social concerns. As a direct and major consequence, the very conceptualization of cultural capital should now take into consideration the plurality of aesthetic paradigms at play in its formation. All of this is in line with the idea of 'emerging' forms of cultural capital (Prieur and Savage, 2013), which translates the adhesion to new or, maybe more accurately, previously scorned values by high-status groups, such as tolerance, fun, interactivity and intervention (e.g. Ardenne, 2004; Bourriaud, 2003). This idea of emerging cultural capital illustrates that the conceptual tools most used in cultural sociology should not be taken for granted; yet, they should be historically contextualized further.

The aesthetically sensitive approach I have taken so far enables me to give a more substantive interpretation of the figure of the 'cultural omnivore', which has most famously challenged the irreducible tensions between high and popular culture. Omnivores, usually highly educated and from upper-middle classes, tend to appreciate both high and low(er) forms of culture (Peterson and Kern, 1996; Peterson and Simkus, 1992). There is now a consensus among numerous cultural sociologists to see it as a source of distinction (Bryson, 1996; Coulangeon and Lemel, 2007) since omnivores do not like 'everything indiscriminantly' (Peterson and Kern, 1996, p. 904). High cultural capital would then now draw on a wider range of cultural goods and activities whose legitimacy is diverse but whose combination is socially valued. Interestingly, Lizardo and Skiles (2012) have seen omnivorousness as an 'aesthetic disposition' that enable people to see the formal and aesthetic attributes of a wide range of objects, including common ones. This capacity to distinguish form from function has emerged, as we know, alongside the autonomization of the art sphere at the end of the $19^{\text {th }}$ century. For Lizardo (2008), the current conditions have changed with the 'intellectualization' of popular culture and the increasing permeability of high culture to popular aesthetics but, for him and his colleague, this has led to the generalization of this rather modernist aesthetic disposition 'outside the canonical domains' (Lizardo and Skiles 2012, p. 269). Although convincing, this account also gives a shallow impression of postmodernist aesthetics, which would be 'just' the consequence of the wider scope of an ultimately very modernist aesthetic disposition (see also for a critique Daenekindt, 2017). However, as we have just seen, a look at recent artistic and cultural developments suggests that omnivorousness would also (if not mainly) translate new schemes of perception emerging from new aesthetic paradigms based on a deconstructive approach to art and on subversion, pastiche, irony, playfulness, and 'de-differentiation' (on which: Lash, 1988 but

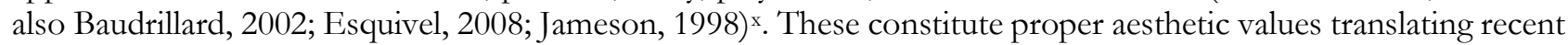
developments in the field of cultural production, which have influenced individuals' dispositions towards art.

To draw on my previous example of video games increasingly perceived as art by key taste makers (but not without resistance), it is evident that this change in the existing cultural classifications can alter what can be conceived as cultural capital: a disposition that allows people to see video games in aesthetic terms can arguably contribute to the development of new 'emerging' forms of cultural capital (see also Friedman et al., 2015). Such appreciation and knowledge in video games, indeed, form new resources on which people can draw and that are not symbolically accessible to everyone. This does not challenge the link between cultural capital and highbrow culture but would suggest that there may as well be now different forms of highbrow cultures, which can for instance take a more classic or contemporary outlook. The multiplicity of highbrow culture has been clearly illustrated by the position of our two critics Stuart and Jones on the matter of the artistic quality of video games. Again, highbrow culture cannot be merely defined by the symbolic value given to people who like it.

\section{Proposition 4: Aesthetics and Morality}

This article has attempted so far to show the importance of aesthetic values in the formation of people's tastes. Even if they emerge out of social and historical processes, they often unconsciously motivate our appreciation of a cultural object or our dislike for it. Aesthetic values also intrinsically carry a moral dimension, making them even more crucial in accounts of tastes. As Wolff argues, the modernist idea of art for art's sake may have hidden the link between aesthetics on the one hand and ethics and the political on the other but that, now that this idea is less dominant, it becomes clearer that ethics and aesthetics are 'bound up together' (2008, p. 138). 
Formal aesthetic values question, challenge and also suggest life visions. Wolff discusses the example of the Holocaust and shows how ethical issues can have a part in discussions about what should or should not be represented in arts but also how influencing directly issues of aesthetics. The aesthetic is hence inseparable from the ethicalxi. As Wolff rightly says, '[t]he pretense of impartiality and the defense of a purely aesthetic motivation can no longer be maintained in our time. [...] The work of art [...] always meets its viewer, even at its most nonrepresentational, in the context of a specific social and historical moment in which the aesthetical, the ethical, and the political, as we know, are never quite separable' (2008, p. 141).

A few sociologists have shown how cultural preferences could be justified on the basis of moral principles xii (Heinich, 1998a, 1998b; Woodward and Emmison, 2001) but their focus is more on how separate ethical and artistic registers of values can be explicitly used in people's justifications of their tastes. For instance, this can be used to understand why many would now make a point of not listening to the songs of Noir Désir, a once adored French rock band that fell in decline after his lead singer was guilty of the homicide of his partner. Meyer (2000) also links tastes to different historically situated 'rhetorics' but, compared to others, he seems to suggest that these rhetorics may influence people's dispositions in specific institutional contexts. They can also be more explanatory than 'classical sociological variables alone' (p. 49). According to him, in a pluralistic society, models of taste-making should not only focus on one form of discourse to assess art that would be primarily associated with the upper classes - a discourse of 'refinement' - but should incorporate other aesthetic rhetorics that would explain the increase level of eclecticism, such as that of 'authenticity' (which based on Rousseau has a strong civic resonance). This adds weight to Vaisey's differentiation (2009) between a 'discursive consciousness' (i.e. how people make sense a posteriori of their behaviours and choices) and a 'practical consciousness' taking the form of dispositions shaping people's courses of action. Seeking to demonstrate the importance of internalized moral-cultural scripts to account for behaviours and choices, Vaisey follows here Sayer's conception (2005b) of the habitus as being composed of not only aesthetic but also of ethical dispositions which would also be historically developed xiii. As he notes, 'Sayer revives parts of the classical notion of habitus that Bourdieu ignored and invites us to extend the logic of Bourdieu's theory from "good music" or "good art" to "the good" more generally" (p. 1685). He seeks here to show how the mechanisms of classification at work in one area - the aesthetics - are also deployed in the second - the morality.

Therefore, just as I have argued for aesthetic values, morality seems also to provide evaluative schemes of perceptions that are not reflexive and conscious - at least not in a deliberative way - but that still have a major role in guiding people in their everyday life, including in what (and how xiv) they like and appreciate and what they do not. I want to extend such a view and to explore how both sets of dispositions interact to shape taste and not only to justify them. More specifically, I would like to go a step further here: not only morality and aesthetics work with similar classificatory mechanisms (good versus bad); they also interact in the formation of tastes because they emerge from the same generative process, i.e. the habitus. The previous example on Noir Désir illustrates that moral principles can make people disregard cultural products (more or less) consciously but morality and aesthetics are more much intertwined than that. To quote Becker, 'people do not experience their aesthetic beliefs as merely arbitrary and conventional; they feel that they are natural, proper and moral. An attack on a convention and an aesthetic is also an attack on a morality' $(1974$, p. 773$)$. This could be applied to any behaviour that can be judged as an aesthetic transgression. Any visible sign of tastes that is not in line with people's aesthetic standards classifies their holders as unconventional at best but most likely as deficient. Therefore, what is perceived as aesthetically problematic may be classified as morally low and, vice-versa, what is perceived as morally disputable may be judged as of bad aesthetic quality. Such reciprocity is essential for those interested in tastes as a defining part of people's lifestyle. As Guyer put it analyzing Kant's philosophical work, '[a] esthetic ideas render moral conceptions accessible to sensibility'. If this serves art as a condition for remaining captivating, this is also essential for the diffusion of moral conceptions: 'at the end of the Critique of Aesthetic Judgment Kant implies that the significance of taste lies in its unique capacity to provide sensible representation of moral ideas' (1990, p. 142). Kendrick Lamar's music, for instance, has been aesthetically praised because it portrays 'the complexity of modern African-American life' in an 'authentic' and 'affecting' ways ${ }^{\mathrm{xv}}$. By denouncing racism, by telling the lives of Afro-Americans who have to deal with a biased criminal justice system, corruption, the lack of future prospects and everyday violence and by questioning the notions of good and evil, his music definitively is imbued with moral ideas about how we should live together (inspired by his Christian faith).

Moreover, recent works on disgust tend to support the idea that moral and aesthetic values are intrinsically related, through the habitus which historically circumscribed dispositions in general. Lawler, for instance, analyses how the aesthetics of working-classes' lifestyles is perceived by the upper-classes as translating 'ignorance and immorality' (2005, p. 437). People who are defined by a lack of taste (by others), being too popular (referring to Bourdieu's popular aesthetics) or too vulgar, are also seen as lacking good values to live in society and induce disgust in others. As Lawler rightly says, disgust seems so personal and instinctive that its collective dimension could be forgotten. Drawing on aesthetic signals that are related to notions of respectability and good manners, 
disgust is so linked to what the 'guts' tell you that it is possible not to see how it helps classify people into 'us' and 'them'. Going back to the Kantian aesthetic vision which links aesthetics and morality, Lawler shows that 'the properly human is marked out by its innate ability to appreciate beauty (to have 'taste')' and that 'conversely, those lacking this property are lacking in humanity, if not non-human' (p. 439), while reminding us that beauty is not universal but historically and socially situated within class relations. More generally it has become clear over the last thirty years that aesthetic values are essential in the understanding of symbolic struggles and moral domination (Skeggs, 2004) but research on this has been inclined to see aesthetic values as only defined by mechanisms of class and not as also connected to a semi-autonomous cultural field.

What this illustrates is that aesthetics has a hermeneutic power: it classifies people and gives a meaning to these classifications but it does so partly through its intrinsic moral dimension.

\section{TASTES: FLUID BUT STRUCTURED MODEL}

Let us now go back to the model, as shown in Figure 1, and use it to answer the question 'But is it good?' When we listen to a song or contemplate an artwork, it is largely accepted since Bourdieu's Distinction that we unconsciously draw on our cultural resources in order to shape our instinctive reaction to it ('I like it', 'It does not speak to me', etc.). I have emphasised in this article that, if the relation between cultural capital (5) and tastes (7) is well known in the literature, many accounts of tastes do not bother to examine the aesthetic dimension of the cultural capital. Yet, people are immersed during their lives within a multiplicity of aesthetic values that are processed into tacit schemes of perceptions (4) or aesthetic dispositions (i.e. embodied form of cultural capital). These dispositions, which are at work in the development of people's cultural tastes, are not only related to their social position (8) and how they have been brought up, i.e. their social origin (1), but also when. This refers to my first theoretical proposition: taking aesthetic values seriously in a model of taste-making requires to understand how they are socially and historically situated. The set of values and principles (2), especially the aesthetico-moral (3), one can have 'access' to depends not only on the kind of resources they have inherited from their parents and social milieu and acquired later at different stages of their lives but also on their overall socio-historical context (6). The field of cultural production is in constant flux and is characterized by diverse aesthetic transgressions or changes, which influence people's cultural consumption. New aesthetic values and paradigms emerge over time (aesthetic modernism, postmodernism, etc.) and alter and shape the kind of aesthetic values and norms individuals could get familiar with and alters the range of aesthetic principles on which cultural capital can be built, possibly in messy ways (Daenekindt, 2017).

In Figure 1, what I call 'the generative process of aesthetic classifications' refers to the ways in which these aesthetic values reflecting specific individual and socio-historical contexts are therefore absorbed by individuals who transform them into schemes of perceptions and dispositions. I agree here with Daenekindt that the way people internationalise aesthetic values and actually activate them in social situations (i.e. the internal aesthetic classification) do not necessarily reflect the 'external system of aesthetic principles (i.e. in the form of governing aesthetic criteria in the cultural field') (2017, p. 43). Discrepancies exist between the individual level and the principles at work in the cultural field. It does not mean though that individuals are not aware of the aesthetic order (i.e. which aesthetic values are more socially praised) and that they may feel some of level of 'dissonance' in the way they internally process them and rely on them in everyday life (Lahire, 2006; 2008).

Hence, in Figure 1, individuals' cultural capital is activated differently in specific contexts depending on their social position and other socio-demographics (age and place of residence). These socio-economic characteristics are essential to understand why new aesthetic principles are only endorsed by certain social groups whose age, education and social position enable them to acquire new resources. As these resources are then not equally distributed in society and positively distinguish those who possess them, they are often associated with the emergence of new forms of symbolic domination in the social space and hence of new groups of taste markers able to make established cultural codes fold. This has been clearly shown in the example of how the growing perception of video games as art or of hip hop as legitimate can influence the content of highbrow culture and hence of cultural capital. Moreover, and perhaps more importantly here, individuals' cultural capital is also shown in Figure 1 to be influenced by their social position in a less immediate way by confronting individuals with different environments as they progress in their life course. The set of aesthetic values people have at disposal is susceptible to evolve throughout their lifetime (see the loop effect represented by the arrow) (Daenekindt and Roose, 2011).

Our social position and our background are not sufficient to account for which aesthetic values operate when. Otherwise, people's tastes would be characterized by much more intragroup consensus that has been observed. Even among visitors of modern and contemporary art museums, whose level of education is overall high, an important amount of heterogeneity in cultural tastes and practices has been observed (Hanquinet, 2013a, 2013b). Hence, the role of aesthetic values has to be examined seriously and, if we want to do that, I have argued that we 
need to consider three other important implications. First, even if inscribed within social forces and transformations, aesthetic values, once internalised, guide us in the evaluation of cultural objects we are confronted with in a semi-autonomous way (proposition 2). They have a force of their own in the sense that social position and origin can only partly 'predict' what aesthetic principles make a cultural product worthy to us. These principles, for themselves and not as a proxy of social background, motivate our cultural preferences, even if we cannot necessarily explain them rationally. Yet, social research has not much sought to analyse which aesthetic values are incorporated into people's possibly large and changing repertoires and under which conditions this process happens. This is especially visible in the difficulty sociology has had in updating the content given to cultural capital and highbrow culture despite some valuable attempts to attract attention to our outdated ways of using them (DiMaggio and Mukhtar, 2004; Hanquinet et al., 2014; Prior, 2005). Figure 1 lays the foundation for us to understand why these intrinsically aesthetic concepts are in need of constant updating (proposition 3). Cultural capital is fluid (Prieur and Savage, 2013) and adapts to new inflections in the cultural landscape.

Finally, the last implication of my model outlines further why a rigorous model on taste-making matters. The aesthetic is not only about what is beautiful. It is also about sharing and debating life visions and is hence intrinsically bound up with morality (proposition 4). Tastes are not trivial differences but can create quite rigid boundaries between people because they contain principles of life people want to adhere to or to reject. We would not have sometimes intense instinctive rejection ('a gut reaction') or 'disgust' of some music or art if the only reason was that it is not aesthetically pleasing. It disturbs us because it challenges our perceptions of what we have established to be good and bad ways of life. In contrast, tastes can also bring people together by emphasising their commonalities and create 'interpretive communities' (Fish, 1980).

In conclusion, this article has provided a thorough demonstration of the main reasons why aesthetic values should be taken seriously by the researchers seeking to understand the formations of tastes. This has designed a model of taste-making in which taste is shown to be influenced by social origin and position but in a much more indirect way that it is often assumed. First these characteristics condition the set of values people are embedded in - according to the social context they live in - and second they influence the practical selection of aesthetico-moral values people operate in the development of their cultural capital. Far from being universal, these aesthetic values should be seen as originating from specific social and historical contexts (hence through social forces); yet, once formed, they impact on people's tastes, in a semi-autonomous fashion. They have a force of their own, which should be studied in itself and not only reduced to social divisions.

\section{REFERENCES}

Ahearne, J. (2004). Between Cultural Theory and Policy: The Cultural Policy Thinking of Pierre Bourdieu, Michel de Certeau and Régis Debray. Centre for Cultural Policy Studies, University of Warvick, Research Papers, 7.

Ardenne, P. (2004). Un art contextuel. Paris: Flammarion.

Baudrillard, J. (2002). The Ectasy of Communication. In H. Foster (ed.), The Anti-Aesthetic. Essays on Postmodern Culture (2nd ed., pp. 145-154). New York: The New Press.

Becker, H. S. (1974). Art as collective action. American Sociological Review, 39(6), 767-776. https://doi.org/10.2307/2094151

Bennett, T., Savage, M., Silva, E., Warde, A., Gayo-Cal, M. and Wright, D. (2009). Culture, Class, Distinction. London: Routledge. https://doi.org/10.4324/9780203930571

Born, G. (2005). On Musical Mediation: Ontology, Technology and Creativity. Twentieth-Century Music, 2(01), 7-36. https:// doi.org/10.1017/S147857220500023X

Bourdieu, P. (1979a). La distinction. Paris: Editions de Minuit.

Bourdieu, P. (1979b). Les trois états du capital culturel. Actes de La Recherche En Sciences Sociales, 30, 3-6. https://doi.org/10.3406/arss.1979.2654

Bourriaud, N. (2003). Esthétique relationnelle. Dijon: Les Presses du réel.

Bryson, B. (1996). "Anything But Heavy Metal": Symbolic Exclusion and Musical Dislikes. American Sociological Review, 61(5), 884-899. https:/ / doi.org/10.2307/2096459

Chaumier, S. (2010). L'inculture pour tous. La nouvelle utopie des politiques culturelles. Paris: L'Harmattan.

Cohen, T. (1999). High and low art, and high and low audiences. The Journal of Aesthetics and Art Criticism, 57(2), 137-143. https://doi.org/10.2307/432308

Coulangeon, P. and Lemel, Y. (2007). Is 'distinction' really outdated? Questioning the meaning of the omnivorization of musical taste in contemporary France. Poetics, 35(2-3), 93-111. https://doi.org/10.1016/j.poetic.2007.03.006

Daenekindt, S. (2017). On the structure of dispositions. Transposability of and oppositions between aesthetic dispositions. Poetics, 62, 43-52. https://doi.org/10.1016/j.poetic.2017.01.004 
Daenekindt, S. and Roose, H. (2013). A mise-en-scène of the shattered habitus: The effect of social mobility on aesthetic dispositions towards films. European Sociological Review, 29(1), 48-59. https://doi.org/10.1093/esr/jcr038

Daenekindt, S. and Roose, H. (2017). Ways of preferring: Distinction through the 'what' and the 'how' of cultural consumption. Journal of Consumer Culture, 17(1), 25-45. https://doi.org/10.1177/1469540514553715

DeNora, T. (1999). Music as a technology of the self. Poetics, 27, 31-56. https://doi.org/10.1016/S0304422X(99)00017-0

DiMaggio, P. (1997). Culture and Cognition. Annual Review of Sociology, 23(1), 263-287. https://doi.org/10.1146/annurev.soc.23.1.263

DiMaggio, P. and Mukhtar, T. (2004). Arts participation as cultural capital in the United States, 1982-2002: Signs of decline? Poetics, 32(2), 169-194. https://doi.org/10.1016/j.poetic.2004.02.005

Esquivel, P. (2008). L'autonomie de l'art en question. Paris: L'Harmattan.

Featherstone, M. (1991). Consumer Culture \& Postmodernism. London: Sage; Theory, Culture and Society.

Fish, S. (1980). Is there a text in this class? The Authority of Interpretive Communities. Cambridge: Harvard University Press.

Friedman, S. (2011). The cultural currency of a "good" sense of humour: British comedy and new forms of distinction. The British Journal of Sociology, 62(2), 347-70. https://doi.org/10.1111/j.1468-4446.2011.01368.x

Friedman, S., Savage, M., Hanquinet, L. and Miles, A. (2015). Cultural Sociology and New Forms of Distinction. Poetics, 53, 1-8.

Hanquinet, L. (2013a). Mondrian as kitchen tiles? Artistic and cultural conceptions of art museum visitors in Belgium. Cultural Trends, 22(1), 14-29. https://doi.org/10.1080/09548963.2013.757892

Hanquinet, L. (2013b). Visitors to modern and contemporary art museums towards a new sociology of 'cultural profiles.' The Sociological Review, 61(4), 790-813. https:// doi.org/10.1111/1467-954X.12072

Hanquinet, L., Roose, H. and Savage, M. (2014). The Eyes of the Beholder: Aesthetic Preferences and the Remaking of Cultural Capital. Sociology, 48(1), 111-132. https://doi.org/10.1177/0038038513477935

Hanquinet, L. (2017). Inequalities: when culture becomes a capital. In Durrer, V., O'Brien, D. and Miller, T. (eds.), Routledge Companion to Global Culture Policy (pp. 327-340). London: Routledge.

Harrington, A. (2004). Art and Social Theory. Cambridge: Polity Press.

Heinich, N. (1991). La gloire de van Gogh. Essai d'anthropologie de l'admiration. Paris: Editions de Minuit.

Heinich, N. (1998a). L'art contemporain exposé aux rejets. Paris: Editions de Minuit.

Heinich, N. (1998b). Le triple jeu de l'art contemporain. Paris: Editions de Minuit.

Hennion, A. (2001). Music Lovers: Taste as Performance. Theory, Culture \& Society, 18(5), 1-22. https://doi.org/10.1177/02632760122051940

Hennion, A. (2007). Those Things That Hold Us Together: Taste and Sociology. Cultural Sociology, 1(1), 97-114. https://doi.org/10.1177/1749975507073923

Jameson, F. (1998). Postmodernism and Consumer Society. In H. Foster (ed.), The Anti-Aesthetic. Essays on Postmodern Culture (2nd ed., pp. 127-144). New York: The New Press.

Kaszynska, P. (15 January 2014). Sociology and Art - the estranged bedfellows, post on the website The \#culturalvalue Initiative. Available at: http://culturalvalueinitiative.org/2014/01/15/sociology-art-estranged-bedfellowspatrycja-kaszynska/ (Accessed 20 June 2014).

Lahire, B. (2006). La culture des individus. Dissonances culturelles et distinction de soi. Paris: La découverte.

Lahire, B. (2008). The individual and the mixing of genres: Cultural dissonance and self-distinction. Poetics, 36(23), 166-188. https://doi.org/10.1016/j.poetic.2008.02.001

Lamont, M. (1992). Money, Morals, and Manners. The Culture of the French and the American Upper-Middle Class. Chicago: The University of Chicago Press. https://doi.org/10.7208/chicago/9780226922591.001.0001

Lash, S. (1988). Discourse or Figure? Postmodernism as a 'Regime of Signification”.' Theory, Culture \& Society, 5(2), 311-336. https:// doi.org/10.1177/0263276488005002006

Lawler, S. (2005). Disgusted subjects: the making of middle-class identities. The Sociological Review, 53(3), 429-446. https:// doi.org/10.1111/j.1467-954X.2005.00560.x

Levine, L. (1990). Highbrow/ Lowbrow. The emergence of cultural bierarchy in America. Cambridge: Harvard University Press.

Lizardo, O. (2004). The Cognitive Origins of Bourdieu's Habitus. Journal for the Theory of Social Behaviour, 34(4), 375401. https:// doi.org/10.1111/j.1468-5914.2004.00255.x

Lizardo, O. (2008). The question of culture consumption and stratification revisited. Sociologica, 2, 1-32.

Lizardo, O. and Skiles, S. (2012). Reconceptualizing and Theorizing "Omnivorousness": Genetic and Relational Mechanisms. Sociological Theory, 30(4), 263-282. https://doi.org/10.1177/0735275112466999 
Lizardo, O. and Skiles, S. (2015). Musical taste and patterns of symbolic exclusion in the United States 1993-2012: Generational dynamics of differentiation and continuity. Poetics, 53, 9-21. https://doi.org/10.1016/j.poetic.2015.08.003

Meyer, H.-D. (2000). The Role of Rhetorics and Institutions. International Sociology, 15(1), 33-56. https://doi.org/10.1177/0268580900015001003

Peterson, R. and Kern, R. (1996). Changing highbrow taste: from snob to omnivore. American Sociological Review, 61(5), 900-907. https://doi.org/10.2307/2096460

Peterson, R. and Simkus, A. (1992). How Musical Tastes Mark Occupational Status Groups. In M. F. M. Lamont (Ed.), Cultivating Differences. Symbolic boundaries and the making of inequality (pp. 152-187). Chicago: The University of Chicago Press.

Prieur, A. and Savage, M. (2013). Emerging Forms of Cultural Capital. European Societies, 15(2), $246-267$. https://doi.org/10.1080/14616696.2012.748930

Prior, N. (2005). A question of perception: Bourdieu, art and the postmodern. The British Journal of Sociology, 56(1), 123-39. https://doi.org/10.1111/j.1468-4446.2005.00050.x

Sayer, A. (2005a). Class, Moral Worth and Recognition. Sociology, 39(5), 947-963. https://doi.org/10.1177/0038038505058376

Sayer, A. (2005b). The Moral Significance of Class. Cambridge: Cambridge University Press. https://doi.org/10.1017/CBO9780511488863

Shusterman, R. (1991). Form and Funk: the Aesthetic Challenge of Popular Art. The British Journal of Aesthetics, 31(3), 213-213. https://doi.org/10.1093/bjaesthetics/31.3.213

Skeggs, B. (2004). Class, Self, Culture. London: Routledge.

Skeggs, B. (2009). The moral economy of person production: the class relations of self-performance on 'reality' television. The Sociological Review, 57(4), 626-644. https://doi.org/10.1111/j.1467-954X.2009.01865.x

Smith Maguire, J. and Matthews, J. (2012). Are we all cultural intermediaries now? An introduction to cultural intermediaries in context. European Journal of Cultural Studies, 15(5), 551-562. https://doi.org/10.1177/1367549412445762

Stewart, S. (2012). Reflections on sociology and aesthetic value. Distinktion: Scandinavian Journal of Social Theory, 13(2), 153-167. https://doi.org/10.1080/1600910X.2011.613483

Strandvad, S. M. (2012). Attached by the Product: A Socio-Material Direction in the Sociology of Art. Cultural Sociology, 6(2), 163-176. https://doi.org/10.1177/1749975512440227

Vaisey, S. (2009). Motivation and Justification: A Dual-Process Model of Culture in Action. American Journal of Sociology, 114(6), 1675-1715. https:// doi.org/10.1086/597179

Wolff, J. (2008). The Aesthetics of Uncertainty. New York: Columbia University Press.

Woodward, I. and Emmison, M. (2001). From aesthetic principles to collective sentiments: The logics of everyday judgements of taste. Poetics, 29(6), 295-316. https:/ / doi.org/10.1016/S0304-422X(00)00035-8

Wacquant, L. (1996). Foreword to the English-language translation of Pierre Bourdieu, The State Nobility. In Bourdieu, P. The State Nobility (pp. VIII-XXII). Cambridge: Polity Press.

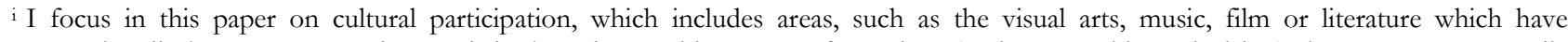
conventionally been consecrated as 'artistic' but also a wider range of practices (such as watching television) that are not necessarily recognized as belonging to the artistic realm but still are part of a cultural lifestyle.

ii Bourdieu distinguishes taste as 'a system of schemes of perception and appreciation' and tastes as 'classified and classifying practices, i.e. distinctive signs' (1984: 171). In this paper, I will from now on refer to the latter definition.

iii In Bourdieu's view, the popular classes tend to be attracted by what is left unconsumed or seen as unworthy by the upper and middle classes. His approach tends to deny any real aesthetic character to popular culture (Shusterman 1991).

iv Coscarelli, J. (16/04/18). Kendrick Lamar Wins Pulitzer in 'Big Moment for Hip-Hop'. The New York Times. Available at: https://www.nytimes.com/2018/04/16/arts/music/kendrick-lamar-pulitzer-prize-damn.html (Accessed 14 November 2018).

v Idem

vi UCLA Newsroom (25/11/18). Rapper Kendrick Lamar winning the Pulitzer Prize for music: What does it mean? Four UCLA professors on the prize going to a non-classical or non-jazz record for the first time ever. Available at: http://newsroom.ucla.edu/stories/kendricklamar (Accessed 14 November 2018)

vii Available at: https://www.theguardian.com/artanddesign/jonathanjonesblog/2012/nov/30/moma-video-games-art (Accessed 20 December 2018)

viii Stuart, K. (06/12/12), Are video games art: the debate that shouldn't', The Guardian. Available at:

https://www.theguardian.com/technology/gamesblog/2012/dec/06/video-games-as-art (Accessed 20 December 2018)

ix It is semi-autonomous for three reasons: 1) their emergence is rooted in social transformations, 2) their internalisation into dispositions is dependent on people's social background and positions and 3) their activation takes place in interactions.

x However, these new developments and values are not always seen positively by the authors mentioned here.

xi Following Sayer (2005b), even if a difference between moral and ethics can be drawn, I will not distinguish moral and ethical values here.

xii The role of morality in drawing symbolic boundaries has also been outlined by Lamont (1992) in her critique of Bourdieu but she focuses only on conscious 'repertoires of evaluation' (see also Vaisey 2009: 1685).
} 
xiii Sayer himself recognizes that 'the distinction between aesthetics and ethics is sometimes fuzzy' (2005b, p. 290).

xiv On this difference, see Daenekindt and Roose (2017).

xv Coscarelli, J. (16/04/18). Kendrick Lamar Wins Pulitzer in 'Big Moment for Hip-Hop'. The New York Times. Available at: https://www.nytimes.com/2018/04/16/arts/music/kendrick-lamar-pulitzer-prize-damn.html (Accessed 14 November 2018) 